\title{
Portuguese and Brazilian stock market integration: a non-linear and detrended approach
}

\author{
Paulo Ferreira ${ }^{1,2,3}$ (D)
}

Received: 5 December 2016 / Accepted: 23 January 2017 /Published online: 10 February 2017 \# ISEG 2017

\begin{abstract}
Besides the historical heritage that Portugal and Brazil share, the last two decades have also shown an increase in some economic indicators, such as the percentage of imports/exports and foreign direct investment. In order to take advantage of all the benefits, the countries should increase economic integration, stock market integration being one of the possibilities. In this context, this paper analyses stock market integration between these two countries, using non-linear methodologies: detrended fluctuation analysis, detrended cross-correlation analysis and detrended moving-average cross-correlation analysis. Using the main stock indexes, and splitting the sample in six different periods, the main conclusion is that integration between these two countries increased over time. However, since 2013, the integration pattern has decreased, with the economic crisis both countries suffered being the main factor.
\end{abstract}

Keywords Brazil - Detrended fluctuation analysis - Detrended cross-correlation analysis · Detrended moving-average cross-correlation analysis $\cdot$ Portugal $\cdot$ Stock market integration

JEL classification $\mathrm{C} 19 \cdot \mathrm{C} 58 \cdot \mathrm{G} 15$

Paulo Ferreira

pjsf@uevora.pt

1 CEFAGE-UE, IIFA, Universidade de Évora, Largo dos Colegiais 2, 7000 Évora, Portugal

2 Escola Superior Agrária de Elvas, Instituto Politécnico de Portalegre, Portalegre, Portugal

3 Universidade Europeia, Lisbon, Portugal 